EDITORIAL INVITADA

Rev Chil Salud Pública 2013; Vol 17 (1): 6-7

\title{
La ley que hace visible a los no fumadores
}

\author{
THE LAW THAT MAKES NONSMOKERS VISIBLE
}

En Chile hay más de 5 millones de fumadores/as.

Cada media hora muere una persona en nuestro país por enfermedades causadas por el tabaco: son, en promedio, 46 muertes diarias, 16 mil cada año. Ostentamos uno de los más tristes récords internacionales que puede tener un país: ser el más fumador del continente americano y tener la prevalencia más alta en el mundo de jóvenes fumadores/as: 39,8\% en el tramo de 13 a 15 años. La Encuesta Nacional de Salud 2009-2010 reveló que el 40,6\% de la población mayor de 15 años fuma, lo que implica una disminución insignificante de 1,4 puntos entre 2003 y 2009 . Uno de los índices más alarmantes de este estudio es el aumento de la intensidad de consumo: de 8 cigarrillos diarios que fumaban los/as chilenos/as en 2003 hoy fuman 10,4.

La magnitud de la epidemia del tabaquismo en Chile y el escaso impacto sanitario de la ley promulgada el año 2006 justificaban de sobra una nueva legislación que regulara el consumo de tabaco en nuestro país. Era necesaria, en primer lugar, para mejorar la salud de la población -especialmente la de fumadores pasivos- y, secundariamente, para cumplir con el Convenio Marco de Control del Tabaco, compromiso internacional vinculante adquirido por Chile el año 2005 con la Organización Mundial de la Salud.

El tabaquismo es una epidemia cuyo vector de transmisión es la industria del tabaco, multimillonaria, transnacional y poderosísima, no sólo por la cantidad de dinero que gana a costa de la salud de la gente, sino por la red de influencias al más alto nivel político que maneja. El propio Ministro de Salud y algunos congresistas denunciaron, en enero pasado, las presiones que han recibido de esta industria para evitar una nueva legislación, más moderna y efectiva en el control de esta epidemia. El inicio del consumo a tempranísimas edades -los niños y niñas chilenos/as empiezan a fumar antes de los 14 años- ha sido el mejor triunfo que las tabacaleras han tenido desde que se instalaron en Chile, a principios del siglo pasado.

Aun así y gracias a una sociedad civil organizada y a la voluntad política de muchos parlamentarios y del Ministerio de Salud, se ha logrado la promulgación de una nueva normativa que consagra, esencialmente, el derecho de los no fumadores a estar, entretenerse y trabajar en ambientes libres de humo de tabaco. Frente a esto, se ha tratado de plantear una polémica que pone en contrapunto la salud de la población y las libertades personales. Este es un dilema inaceptable desde la perspectiva de la salud pública. No se puede defender el derecho de los fumadores y no hacerlo con los no fumadores. Son estos últimos los que se han invisibilizado durante décadas y muchos de ellos se convirtieron en fumadores pasivos sin 
desearlo. ¿Qué libertad protegemos, entonces? ¿La de dañar a quien está al lado sin su consentimiento?

$\mathrm{Al}$ igual que lo ocurrido recientemente con la llamada ley de "tolerancia cero al alcohol", se espera que la nueva ley del tabaco demuestre, en el mediano plazo, impacto sanitario tanto en la disminución de las altas prevalencias que hoy tenemos, en las muertes atribuibles al consumo de tabaco y en la alta morbilidad aguda y crónica causada por esta enfermedad.

Con esta nueva ley Chile se pone a la altura de las políticas públicas que a nivel mundial se han promovido para controlar la epidemia del tabaquismo. Enhorabuena. 